\section{DIRETRIZES CURRICULARES NACIONAIS DA EDUCAÇÃO FÍSICA: DO REAL APARENTE A UMA SÍNTESE POSSÍVEL}

\section{NATIONAL CURRICULAR GUIDELINES OF PHYSICAL EDUCATION: FROM REAL TO A POSSIBLE SYNTHESIS}

Jorge Adilson Gondim Pereira ${ }^{1}$

\section{INTRODUÇÃO}

A tese de que as atuais Diretrizes Curriculares da Educação Física, supostamente responsável pela divisão da formação em licenciatura e bacharelado é fruto de determinação de uma lógica neoliberal capitaneados por segmentos conservadores da Educação Física, entre eles, o Conselho Federal de Educação Física (CONFEF), vem sendo aceita com elevado grau de confiabilidade no campo da Educação Física, em virtude de extensa produção acadêmica que reafirma essa versão, a exemplo de (NOZAKI, 2004; TAFFAREL e LACKS, 2005; TAFFAREL e SANTOS JUNIOR, 2005, 2010; VENTURA, PRONI, 2010; DIAS e TEIXEIRA, 2011; IORA et ali, 2017; DE PAULA et ali, 2018) e diversos outros trabalhos facilmente disponíveis em plataformas on-line de busca científica utilizando descritores como: divisão da formação, licenciatura e bacharelado, CONFEF e a formação em Educação Física, entre outros relacionados com a questão.

Trata-se de um maniqueísmo em torno desse fato histórico que, conforme narram e defendem, um grupo ficou em defesa dos trabalhadores da Educação Física, enquanto outro, num consenso escuso, decretou a divisão da formação em Educação Física.

\section{RESUMO}

Este artigo interpreta o processo de elaboração histórica das Diretrizes Curriculares Nacionais da Educação Física. Analisou e comparou publicações e depoimentos a fim de apresentar elementos novos à discussão. Explicita a vertente idealizada de muitas interpretações presentes no campo acadêmico da atualidade e conclui que o documento expressa o resultado da correlação de forças políticas e interesses antagônicos em sua elaboração.

Palavras-chave: Formação Profissional; Educação Física; Diretrizes Curriculares Nacionais.

\section{ABSTRACT}

This article interprets the process of historical elaboration of the Guidelines National Curriculares of the Physical education. It analyzed and it compared publications and depositions in order to present new elements to the discussion. Explicit the idealized slope of many present interpretations in the academic field of the present time and it concludes that the document expressed the result of the correlation of political forces and antagonistic interests in her elaboration.

Keywords: Professional Formation; Physical Education; Guidelines National Curriculares

Submetido em: 31 de mai. 2018

Aceito em: 06 de nov. 2018 
Resguardada as proporções, as ideias vinculadas por esses autores cultivam um certo antagonismo às atuais diretrizes que têm como base questões essencialmente ideológicas, impedindo ao conjunto de professores do campo de avaliarem melhor as possibilidades e avanços deste documento quando comparado aos modelos anteriores de formação profissional.

O que percebemos é que a narrativa de quem condena, estruturase de modo a deixar evidente a participação do CONFEF como principal agente no processo de aprovação das diretrizes. A impressão é que a participação do CONFEF e dos setores conservadores da Educação Física é superestimada enquanto os outros participantes, a exemplo dos representantes do Colégio Brasileiro de Ciências do Esporte (CBCE) e do Ministério do Esporte é subestimada. Mais a frente, detalharemos e contextualizaremos melhor a premissa que anunciamos nesse parágrafo.

Portanto, abrimos espaço para analisar a história desse acontecimento a partir de óticas diferentes, seja dos setores progressistas da Educação Física que não admitiram participar do processo de construção e aprovação do substitutivo final - parecer 058/04 - ou dos setores progressistas vinculados ao CBCE e Ministério do Esporte que foram favoráveis a este. Para tanto, pesquisamos trabalhos acadêmicos dedicados a essa história, tendo nos ocupado das teses de Doutorado dos professores Hajime Nozak (2004) e Paulo Ventura (2010), além de artigo das professoras Celi Taffarel e Solange Lacks (2005). Utilizamos também a fala do professor Lino Castellani Filho em debate com a professora Celi Taffarel na $64^{\mathrm{a}}$ Reunião Anual da Sociedade Brasileira para o Progresso da
Ciência (SBPC) em 2012. O intuito foi confrontar as histórias contadas de modo a identificar seus nexos e contradições na tentativa de acrescentar ao debate novos dados e novas formas de compreensão em relação a este importante fato histórico.

\section{REVENDO DADOS SOBRE A ELABORAÇÃO E REVOGAÇÃO DO PARECER CNE/CES N ${ }^{\circ}$ 138/02}

O processo de construção das diretrizes curriculares para a Educação Física foi disparado pelo Conselho Nacional de Educação (CNE) por meio do Parecer 776/97, tornando pública a convocação para que todas as Instituições de Ensino Superior (IES) interessadas apresentassem propostas para a construção das novas diretrizes curriculares dos seus cursos superiores. No caso da Educação Física, foi feito o aprimoramento da Resolução 03/87, bem como a correção de algumas distorções constatadas ao longo dos doze anos de vigência, segundo os membros da primeira Comissão de Especialistas de Ensino em Educação Física (CO$E S P$ ) - em publicação de artigo na Revista Brasileira de Ciências do Esporte (RBCE) (KUNZ, 1998).

A justificativa da comissão para a criação do bacharelado se deu pela manifestação das IES de que a formação do licenciado não desenvolvia as competências e qualificações necessárias para a intervenção profissional nos diversos campos de trabalho não-escolar.

Destarte, as distorções mais polêmicas geradas no âmbito dessa discussão diziam respeito à interpretação do que seria o bacharelado: especialização/aprofundamento e/ou formação geral/básica e aplicada, bem como à interpretação dicotomizada da atuação profissional em função da dupla graduação: intervenção escolar (licenciatura) e/ou intervenção não escolar (bacharelado) (ANDRADE FILHO, 2001).

Fato concreto é que, embora esse modelo tenha gerado polêmicas e contrariado a comunidade acadêmica comprometida com uma formação mais humana e crítica, não pôde vir a cabo em virtude da publicação do Parecer 009/2001 que estabeleceu Diretrizes Curriculares para a Formação de Professores da Educação Básica, em nível superior, Curso de Licenciatura de Graduação Plena, e o Parecer 021 /2001 que dispõe sobre a duração e carga horária dos cursos de Formação de Professores, mais tarde publicados sob a forma das Resoluções CNE/CP $n^{\circ}$ 01/02 e 02/02, diferenciando a licenciatura do bacharelado, estabelecendo terminalidade e integralidade própria a esses cursos.

Com isso, impôs-se a necessidade da criação de Diretrizes para os bacharelados e complementação das especificidades das licenciaturas. É importante ressaltar que

\footnotetext{
As diretrizes para as licenciaturas apontaram para que todas as áreas científicas que tivessem formação pelo bacharelado, se debruçassem para elaborar e aprovar as diretrizes para este modelo de formação, regulamentando as necessidades na formação de bacharéis e complementando as especificidades de suas licenciaturas, naquilo que não entrasse em colisão com as Resoluções para a formação de professores. Esclarecer isso se torna importante, na medida em que não se devam pensar as diretrizes curriculares específicas de cada área do conhecimento, como diretrizes exclusivas para o bacharelado. No entanto, criou-se uma representação, levando a que muitas áreas assim tenham procedido (VENTURA, 2010, p. 144-145).
} 
Em função dessa necessidade, Nozaki (2004) identificaria a ingerência do sistema CONFEF/ Conselho Regional de Educação Física (CREF) por meio do processo de articulação junto aos dirigentes, sobretudo de Instituições privadas, na realização de fóruns regionais e nacionais para discutir assuntos ligados à formação profissional. Além disso, visava formular documentos e textos que objetivassem contribuir com o processo de elaboração das diretrizes curriculares. Segundo ele, isso foi decisivo na elaboração do parecer 138/02.

Além da articulação desenvolvida pelo CONFEF/CREF junto aos dirigentes de Instituições de Ensino privadas, Castellani Filho (2012) sustenta que o referido conselho mantinha uma relação junto à Câmara de Educação Superior, com o conselheiro escolhido para relatar o projeto das Diretrizes curriculares para a Educação Física, o conselheiro Carlos Serpa que, segundo o professor Lino, era carioca e professor de uma Universidade que o professor Jorge Steinhilber, então presidente do Conselho, mantinha laços bastante fortes. Baseado nisso, o CONFEF era então um interlocutor privilegiado junto àquele conselheiro na construção das Diretrizes e, foi justamente ele que construiu o parecer 138 aprovado em 03 de abril de 2002.

Bastante criticado pela comunidade científica da Educação Física, o referido parecer sofreu diversas interpelações. Entre elas, Taffarel e Lacks (2005) citam a que ocorreu na $54^{\mathrm{a}}$ Reunião Anual da SPBC, quando o CBCE conseguiu aprovar a deliberação de enviar carta ao presidente e ao vice-presidente da Câmara Superior do Conselho Nacional de Educação (CP/CNE) e ao coordenador das dire- trizes da área da saúde, solicitando a não aprovação do projeto de resolução que versava sobre as diretrizes da Educação Física e ao ministro da Educação, solicitando a revogação da homologação do Parecer 138/2002. Também em evento organizado pelo CONFEF, durante o período de 15 a 18 do mês de julho de 2002, intitulado II Fórum de Diretores dos Cursos de Educação Física, foi articulado um documento para os mesmos destinatários da carta do CBCE, subscrito por, aproximadamente, 90 das cerca de 120 instituições presentes (Idem, 2005).

Ainda segundo as autoras, o CNE "realizou reuniões nos dias 5 a 7 de agosto de 2002 e acolheu uma solicitação do Ministério do Esporte, decidindo não aprovar o projeto de resolução sobre as diretrizes propostas pelo CONFEF, dispondo-se, ainda, a reabrir as discussões sobre as diretrizes da Educação Física" (TAFFAREL E LACKS, 2005, p. 95).

Por outro lado, Castellani Filho (2012), destacando a participação do CBCE na I Conferência sobre Educação, Cultura e Desporto, promovida pelo Congresso Nacional, Câmara Federal e Comissão de Educação, Cultura e Desporto no ano de 2002, observa que fizeram contatos com representantes do congresso e do CNE mostrando que a construção das diretrizes não vinha se dando de forma a envolver todos os segmentos do campo da Educação Física. Nestes termos, o CNE sinaliza para a abertura de uma nova rodada de negociações, tendo percebido que o processo anterior não havia contemplado todos os segmentos da Educação Física, ou seja, o processo anterior havia ficado restrito ao Conselheiro Carlos Serpa e ao CONFEF.
Essas duas informações, a primeira das professoras e pesquisadoras Celi Taffarel e Solange Laks e a segunda do professor Lino Castellani Filho se apresentam contrastantes em virtude da primeira se referir de modo equivocado ao acolhimento por parte do CNE de uma suposta solicitação do Ministério do Esporte, ainda não existente nesta época. Ao contrário disso, a segunda informação revela o protagonismo do CBCE junto ao CNE, o que, portanto, nos faz entender que o $\mathrm{CNE}$ acolheu uma solicitação do CBCE e não do Ministério do Esporte, até porque, esse Ministério só veio a existir em 2003, no governo Lula. Essa informação é importante, pois os mesmos agentes do CBCE que produziram a ação junto ao CNE em 2002, darão continuidade ao seu protagonismo no ano de 2003, só que dessa vez, por dentro do Ministério do Esporte.

Segundo Castellani Filho (2012), o conselheiro Efrem Maranhão (coordenador das diretrizes da área da saúde/CNE) estabeleceu um tempo aos segmentos da Educação Física para que realizassem os debates e produzissem novas propostas. No mesmo ano, o CBCE promoveu em Campinas um evento com a finalidade de realizar novas discussões, em que foram convidados todos os segmentos da Educação Física, professores, entidades, dirigentes de cursos, CONFEF e movimento estudantil tendo, esse evento, servido de parâmetro para a elaboração de uma diretriz de formação profissional em Educação Física.

Nozaki (2004), Taffarel e Laks, (2005) e Ventura (2010) relatam que, embora o CNE tivesse suspendido a aprovação das diretrizes da Educação Física, com a mudança de governo, aconteceram pressões do CBCE, Ministério do Esporte e Movimento Estu- 
dantil da Educação Física (MEEF) no sentido de interromper a tramitação do parecer 138/02.

À frente da Secretaria Nacional de Desenvolvimento do Esporte e do Lazer (SNDEL) do Ministério do Esporte na época, o professor Lino Castellani Filho narra esse episódio por ocasião de debate travado com a professora Celi Taffarel em mesaredonda com o tema - Formação Profissional em Educação Física: uma antítese que se arrasta... - Realizada na programação do CBCE na $64^{a}$ Reunião Anual da SBPC no dia 25 de julho de $2012 .^{2}$

Em 2003, já no Ministério do Esporte, numa tarde, o futuro Ministro Orlando, então Secretário Nacional de Esporte, me convida para fazer uma visita ao Presidente do Conselho Nacional de Educação, seu conhecido desde o tempo em que era estudante da Universidade Católica do Salvador, BA, sendo o Conselheiro, Reitor da referida Universidade à mesma época. Nessa oportunidade, aproveitei para perguntar ao presidente do Conselho o que vinha sendo feito para ampliar a discussão a respeito do processo de elaboração das diretrizes curriculares da Educação Física. O presidente em consulta ao Efrem Maranhão, coordenador das diretrizes da área da saúde, solicitou que o Secretário da Presidência do Conselho verificasse a situação do parecer $138 / 02$. A informação obtida foi que o relator, Carlos Serpa, estaria se aposentando no mês seguinte e que havia encaminhado o parecer sob a forma de Resolução para a Casa Civil da Presidência, com vistas à sua publicação no Diário Oficial da União. Foi patente, a decepção e o constrangimento do conselheiro Efrem em torno da questão. De volta ao ministério, não me dando por vencido, ligo para a gráfica do Diário Oficial e so-

${ }^{2}$ Mesa-redonda organizada pelo $\mathrm{CBCE}$ na $\mathbf{6 4}^{\mathbf{a}}$ REUNIÃO ANUAL DA SOCIEDADE BRASILEIRA PARA O PROGRESSO DA CIÊNCIA intitulada Formação profissional em Educação Física: uma antítese que se arrasta... Maranhão, São Luis: UFMA, 2012. licito informações quanto à publicação do referido documento. Em resposta, fui informado que o documento se encontrava por ali e que ainda levaria alguns dias para ser publicado. Perguntei se existiria a possibilidade do mesmo ser retirado, tendo obtido resposta de que seria possível a retirada, desde que o órgão que havia solicitado a publicação requeresse a devolução do documento. Diante da informação, liguei para a secretaria do Conselho Nacional de Educação, transmitindo a informação da gráfica e solicitando, portanto, a retirada do documento. Passado alguns dias, ainda incrédulo de que o Conselho fosse, de fato, retirar o documento em virtude da preservação de seus conselheiros, recebo a ligação do referido órgão informando-me que a resolução ali se encontrava. Com isso, foi retirado da gráfica o parecer 138/02 e a aprovação de uma possível resolução nesses mesmos termos (CASTELLANI FILHO in $64^{\mathrm{a}}$ SPBC, 2012).

Portanto, acrescentamos mais essa informação àquelas invariavelmente vistas nas publicações que se dispõem a narrar esse episódio sendo que, a partir dela, acreditamos que a pressão exercida sobre o CNE se deu não pelo órgão Ministério do Esporte, mas, sim por um militante progressista da Educação Física que, chegando ao cargo de Secretário Nacional de Esporte e gozando de prerrogativas e trânsito dentro da máquina governamental, retirou, em condições puramente circunstanciais, embora politicamente guiado, um parecer que estava em vias de ser publicado e que poderia prejudicar sobremaneira a Educação Física. Não conseguimos identificar nesse episódio qual concretamente foi a participação do CBCE e do MEEF, conforme anunciado pelos outros autores.

\section{SUBSTITUTIVO AO PARECER 138/02: CONSENSO OU AVANÇO POSSÍVEL?}

Em virtude do empenho do Professor Lino Castellani, então responsável pela SNDEL no processo de revogação do Parecer 138/02, o Ministério do Esporte passa a ocupar a cena em relação à discussão do seu Substitutivo. É importante destacar que essa não foi uma tarefa fácil em decorrência da resistência de setores conservadores da Educação Física. O professor Castellani Filho destaca que, "por diversas vezes, o CONFEF tentou persuadir o novo relator das Diretrizes, conselheiro Éfren Maranhão, a não aceitar o protagonismo desse órgão de governo tendo, o referido conselheiro, dado como resposta que não estava ali para editar a história" (2012).

Nozaki (2004) assinala, em sua tese, que foi criado um grupo de trabalho a partir do Ministério do Esporte com o objetivo de elaborar uma proposta substitutiva. Posteriormente, a Secretaria de Educação Superior do Ministério da Educação (SESU/MEC) convidou o professor Helder Resende da antiga COESP e um representante do grupo de trabalho para presidirem uma comissão oficial para a reformulação das diretrizes. Agregaram-se a essa comissão, novos membros da antiga COESP, CBCE e do próprio CONFEF. Sobre o grupo de trabalho criado a partir do Ministério do Esporte, o professor Castellani Filho narrou da seguinte forma:

A partir daí foi possível uma nova
rodada de negociações e discus-
sões, de acordo com o Conselho
Nacional de Educação e sob a co-
ordenação do Ministério do Espor-
te, envolvendo o mais amplo espec-
tro da área possível, no sentido de
ter, em sessenta dias, um novo do-
cumento para aprovação, tendo sido
esse o compromisso assumido com
o CNE por meio da interlocução
com o conselheiro Efrem Mara- 
nhão. Para tanto, foram convidados todos os segmentos da área da Educação Física: CBCE, LEPEL, CONDIESEF, CONFEF, EXENE$\mathrm{EF}$, porque não havia hipótese política de o documento ser aprovado sem a anuência do CONFEF e CONDIESEF. Seria ingenuidade pensar que poderia bancar o projeto que vinha sendo discutido no CBCE e, simplesmente, por em cima da mesa exigindo a sua aprovação. Foram convidadas, também, pessoas que vinham apresentando trabalhos na área como o professor Nivaldo David e o professor Helder Resende, este último, pela sua relação com a SESU, ficando o referido professor responsável pela a realização de diversas plenárias de discussões (CASTELLANI FILHO in $\left.64^{\mathrm{a}} \mathrm{SPBC}, 2012\right)$.

Portanto, ao que parece, buscou-se estabelecer o diálogo democrático entre as diversas representações da Educação Física em busca de avançar na proposição, se não de um documento que atendesse todas as reivindicações do campo progressista da Educação Física, pelo menos um melhor do que o parecer $138 / 02 .^{3}$ Realizado o trabalho,

Tratou-se de incluir a SESU/MEC no processo. Coube a mim e ao Orlando a indicação do Helder para presidi-la na ocasião. Em determinado momento de sua composição, o CONFEF liga para o Orlando solicitando assento na comissão da SESU. Orlando, em comum acordo comigo, sinaliza uma vaga; o CONFEF pleiteia duas; Orlando ratifica uma e aponta que seria pegar ou largar. Minutos depois o CONFEF volta a ligar aceitando a vaga e

\footnotetext{
${ }^{3}$ Ainda, relata o professor Lino, que se afastou do processo em virtude de não ser uma pessoa bem quista a determinados setores conservadores e, também, pelo interesse que o debate avançasse em meio há um coletivo tão heterogêneo. Tinha consciência que, em virtude do antagonismo de posições no interior desse coletivo, jamais seria possível a aprovação de um documento que representasse as aspirações de apenas um segmento da área. Desse modo, a estratégia para o momento, seria avançar da configuração conservadora do parecer $138 / 02$.
}

indicando o professor Tojal como seu representante (CASTELLANI FILHO in $\left.64^{\mathrm{a}} \mathrm{SPBC}, 2012\right)$.

Depois de várias reuniões, a comissão de especialistas apresentou uma proposta de substitutivo ao parecer 138/02 no final de 2003, sendo apreciada em audiência pública no dia 15 de dezembro do mesmo ano. Nos dias 12 e 13 de dezembro de 2003, o Grupo de Trabalho Temático "Formação Profissional e Mundo do Trabalho", do Colégio Brasileiro de Ciências do Esporte (CBCE), realizou uma reunião em Vitória, Espírito Santo, analisando-se o referido substitutivo (TAFFAREL e LAKS, 2005). Baseando-se em entendimento anteriores do CBCE e em discussões ocorridas durante a reunião, produziram um documento intitulado "Carta de Vitória", posicionando-se veementemente contra ao parecer 138/02 e ao parecer substitutivo.

É importante destacar alguns aspectos relacionados a esse documento. O primeiro é que para um Coletivo que se dispunha a contribuir com a reflexão sobre as políticas públicas de formação para a Educação Física, é no mínimo estranho se reunir às vésperas da aprovação do substitutivo e se confessar "bastante surpresos com o apoio do CBCE/DN à proposta da COESP”. O segundo, é que um documento dessa monta não poderia assumir contornos inquisitórios tão evidentes ao questionar a legitimidade da participação da professora Zenólia Figueiredo enquan-

\footnotetext{
${ }^{4}$ Em reunião ocorrida entre os dias 12 e 14 de dezembro em Vitória - ES, o GTT 6 - Formação Profissional e Mundo do Trabalho do CBCE, discutiu uma pauta pré-agendada para subsidiar o CBCE/DN, nas políticas de formação profissional, em função dos fatos que cercaram o processo de aprovação das diretrizes, publicando um documento denominado "Carta de Vitória", endereçada à Direção Nacional do CBCE e aos sócios da entida-
} de, expondo uma série de encaminhamentos. to representante da CBCE. Ao mesmo tempo, justifica que "a Sócia Pesquisadora, enquanto representante do CBCE no interior da COESP, por várias vezes, provocou embates e conflitos por tentar avançar na proposta da Comissão". Entretanto, é preciso salientar que a posição da referida professora estava fundamentada no consenso até ali alcançado pelos representantes da COESP. Esta posição pode ser confirmada por meio da sua produção acadêmica (FIGUEIREDO, 2004, 2009; FIGUEIREDO e MARQUES, 2013; FIGUEIREDO e MORAES, 2013) que procura analisar o atual marco regulatório, além de experiências formativas nos cursos de Educação Física reconhecendo limites e possibilidades na formação do professor.

Por último, o documento reporta-se sempre ao Parecer CNE 138/02 e não à proposta substitutiva a ele. Portanto, gera a impressão de que as análises feitas durante a reunião não tiveram como foco de análise a proposta substitutiva talvez por não reconhecer a legitimidade do que vinha sendo construído.

Com efeito, embora o propósito da Carta de Vitória fosse o de repudiar o substitutivo ao parecer 138/02, revela, nos parece, tão somente uma tática política para tornar pública a posição contrária à aprovação do novo Parecer. Ademais, a Carta de Vitória apresenta um posicionamento do GTT que em sua correlação de forças, apontava para a radicalização da questão. Talvez não fosse essa a posição geral da Entidade CBCE.

Isto posto, o substitutivo foi apreciado e aprovado em audiência pública no dia 15 de dezembro de 2003, convocada pelo CNE. Na audiência, o CONFEF se posicionou contra 
o substitutivo e defendeu o parecer 138/02. O MEEF criticou o documento, mas, em sentido contrário, contestando a divisão da formação em licenciatura e bacharelado e suas ligações com a atual fase do capitalismo. Apoiaram o substitutivo o CBCE, o Ministério do Esporte e o Conselho de Dirigentes das Instituições de Ensino Superior de Educação Física (CONDIESEF), fundamentando-se no consenso até ali alcançado.

\section{CONCLUSÃO}

É interessante analisar o motivo pelo qual as Diretrizes aprovadas, consideradas por parte significativa de pesquisadores da Educação Física, um documento conservador e retrógrado, atrelado aos interesses do mercado emergente da Educação Física, teria motivado o CONFEF a posicionar-se contrariamente à sua aprovação. Quais seriam as razões para o CONFEF votar contra o parecer 058/04? Nesta audiência, há relatos que o sistema CONFEF/CREF criticou o documento substitutivo adjetivando-o de "colcha de retalhos" e posicionou-se em defesa do Parecer CNE/CP 138/2002. Isso demonstra que o CONFEF/CREF não se sentiu contemplado com a aprovação deste documento. Com isso, não se pode afirmar que o parecer 058/04 tenha sido objeto do seu protagonismo.

Portanto, a partir desse estudo, é possível concluir que as análises e reflexões que imputam responsabilidade e protagonismo direto do CONFEF ao processo de normatização da formação profissional em Educação Física estão equivocadas.

Ainda sobre a posição do CBCE nesse processo, Taffarel e Laks (2005) assinalam que o CBCE, contraditoriamente à sua função de entidade científica reafirma e/ou corrobora uma resolução que não considera os avanços da área no que diz respeito à teoria do conhecimento e a organização curricular. Ao contrário disso, consideramos que o $\mathrm{CBCE}$ enquanto entidade científica tem a responsabilidade de fomentar o debate teórico e plural contemplando posições ideológicas heterogêneas. Portanto, não cabe a uma entidade científica, notadamente aberta ao processo dialético de construção de ideias e teorias sobre as diversas temáticas que envolvem a produção científica da área, ser representante de um único postulado que não possui consenso interno. Cabe sim, a uma entidade desse nível, compreendendo o momento histórico e as possibilidades de avanço em relação ao documento anterior, contribuir para a construção de um documento mais coerente, que pudesse, em condições negociadas, refletir os interesses da categoria dos professores de Educação Física.

Castellani Filho (2012) reafirma que a divisão da formação não foi um movimento do CONFEF e nem foi um movimento da Educação Física, foi fruto de uma lógica maior iniciada nos finais dos anos 70 e início dos anos 80 do último século, já presente na Resolução 03/1987 que previa a formação em ambas as habilitações, muito embora fosse figurada como uma licenciatura ampla no sentido da intervenção profissional em todos os espaços de trabalho. Ainda observa esse autor que,

A questão central que está posta é que nós não tivemos condições políticas, na correlação de forças estabelecidas, de termos a hegemonia do processo e, diante da ausência de hegemonia, nós construímos o que foi possível. Seria postura política simplista e equivocada traba- lhar na direção de defender o meu projeto ou nenhum, como muitos defendem. Recusaram de participar, o movimento estudantil e a LEPEL que, coincidentemente, apresentaram mesmo documento. Entendo ter havido articulação entre o movimento estudantil e o lepel em suas ações, o que não é ruim em si mesmo. Torna-se preocupante quando se percebe nessa articulação certo aparelhamento da instância estudantil por parte do grupo de pesquisa, sinalizador de uma visão educacional mais próxima à lógica de doutrinação ideológica do que de educação para a autonomia intelectual e política (CASTELLANI FILHO in $64^{\mathrm{a}}$ SPBC, 2012).

Ao finalizarmos esse artigo, esperamos ter contribuído com a discussão sobre o processo de constituição histórica das Diretrizes Curriculares da Educação Física, especialmente, no sentido de desmitificar a ideia de que a Resolução CNE/CES No 07/2004 tenha sido fruto de ingerência exclusiva do CONFEF sobre o CNE.

Pelo que apresentamos aqui, houve ingerências diversas, tanto no sentido da construção de um documento voltado aos interesses de setores conservadores como também de setores progressistas da Educação Física, todas legítimas numa sociedade democrática.

Esses dados e reflexões são importantes, pois nos ajudam a compreender as Diretrizes Curriculares da Educação Física exatamente como elas são, um documento contraditório que expressa bem a correlação de forças políticas e interesses antagônicos em seu processo de elaboração. A contradição nesse caso, não significa demérito ao documento, ao contrário, representa os seus avanços e retrocessos, seus limites e possibilidades e, o mais importante, o reconhecimento de que a luta principal está completamente em aberto no interior das universidades, 
faculdades e centros universitários de todo o país, na elaboração e execução desses currículos. É precisamente nesse espaço que a luta é mais relevante e onde a correlação de forças é também desfavorável aos segmentos mais progressistas da Educação Física.

Portanto, a luta pela revogação das atuais diretrizes como desejam alguns, não parece ser uma boa estratégia em virtude dos "setores progressistas" da Educação Física estarem ainda mais frágeis, dado o recrudescimento da articulação de setores conservadores e retrógrados de nossa sociedade.

O Parecer aprovado pelo CNE de $n^{\circ} 058 / 04$ e materializado pela Resolução CNE/CES no 07/2004 aponta que,

apesar dos seus problemas e dubiedades epistemológicos, como exemplo os inúmeros termos utilizados para representar o objeto da educação física, como se fossem todos advindos de uma única matriz epistemológica, há de se considerar que essa resolução não aprisiona os currículos de formação das IFES, ao contrário, amplia as possibilidades de interpretação para além do campo da saúde, superando a proposição do Parecer CNE/CP 138/20027, articulado pelo Conselho Federal de Educação Física e quase viabilizado oficialmente (FIGUEIREDO e MARQUES, 2013, p. 1-14).

As interpretações comumente feitas em relação ao processo histórico de constituição das Diretrizes da Educação Física, muitas vezes desatentas aos dados da realidade, apreendendo o real aos seus constructos ideopolíticos, têm contribuído apenas para a negação das Diretrizes nas Instituições de Ensino Superior sem, porém, avançar em proposições curriculares inovadoras. A síntese possível aponta para o reconhecimento dos limites das diretrizes ao tempo em que identifica suas possibilidades para a construção e execução de currículos mais críticos, identificados com as demandas humanas e sociais do mundo contemporâneo, entendendo ser esta uma saída mais frutífera para fazer avançar a formação na área da Educação Física.

\section{REFERÊNCIAS}

ANDRADE FILHO, Nelson Figueiredo de. Formação profissional em educação física brasileira: uma súmula da discussão dos anos de 1996 a 2000.

\section{Revista Brasileira de Ciências do}

Esporte, Campinas - SP, v. 22, n.3, p. 23-37, 2001.

BRASIL. Lei de Diretrizes e Bases da Educação Nacional no 9.394, de de-

zembro de 1996. Brasília: Câmara dos Deputados, 1996.

BRASIL. Conselho Federal de Educação. Parecer n. 292, 14 nov. 1962. Diário Oficial da União, Brasília, DF, 1962.

. Conselho Federal de Educa-

ção. Resolução no 03, de 16 de Junho de 1987. Fixa os mínimos de conteúdo e duração a serem observados nos cursos de graduação em Educação Física (Bacharelado elou Licenciatura Plena). Diário Oficial da União, Brasília: DF, 10 set. 1987b.

Conselho Nacional de Educação. Câmara de Educação Superior. Parecer CNE $N^{o} 776 / 97$. Diário Oficial da União, Brasília-DF, 03 de dezembro de 1997.

Conselho Nacional de Educação. Câmara de Educação Superior. Resolução CNE/CES 07/2004. Diário
Oficial da União, Brasília: DF, 31 de março de 2004.

Conselho Federal de Educação. Parecer CNE/CP 09/2001. Diário Oficial da União, Brasília: DF, 08 de maio de 2001.

Conselho Federal de Educação. Parecer CNE/CP 021/2001. Diário Oficial da União, Brasília: DF, 12 de fevereiro de 2001.

. Conselho Federal de Educação. Parecer CNE/CP 138/2002. Diário Oficial da União, Brasília: DF, 03 de abril de 2002.

Conselho Federal de Educação. Resolução CNE/CP 01/2002.

Diário Oficial da União, Brasília: DF, 18 de fevereiro de 2002.

Conselho Federal de Educação. Resolução CNE/CP 02/2002. Diário Oficial da União, Brasília: DF, 19 de fevereiro de 2002.

. Conselho Federal de Educação. Câmara de Educação Superior. Parecer CNE/CES n. 058/04. Diário Oficial da União, Brasília: DF, 18 de fevereiro de 2004.

DE PAULA, Alisson Slider do Nascimento; OLIVEIRA, Rogério Paes de; TESTA, Saulo; COSTA, Frederico Jorge Ferreira . Formação em Educação Física e a regulamentação da profissão: sistema CONFEF/CREFS e a divisão curricular. Debates em Educação-UFAL, v. 10, p. 279-292, Maceió- AL, 2018.

DIAS, F. B. M.; TEIXEIRA, D.R. Formação de professores de educação física: a atualidade do embate político. Motrivivencia (UFSC), v. 35, p. 184201, 2011. 
FIGUEIREDO, Z. C. C. . Formação Docente em Educação Física: experiências sociais e relação com o saber. Movimento (UFRGS. Impresso) Porto Alegre UFRGS, v. 10, p. 89-112, 2004.

FIGUEIREDO, Z. C. C. . Uma Experiência de Formação de Professores de Educação Física na Perspectiva do Formar-se Professor. Pensar a Prática (UFG), v. 12, p. X-X, 2009.

FIGUEIREDO, Z. C. C. ; MARQUES, F. B.. Diretrizes Curriculares Nacionais para os Cursos de Educação Física: fronteiras entre orientações e aprisionamentos legais. CBCE.

<http://cbce.tempsite.ws/congressos/in dex.php/conbrace2013/5conice/paper/ viewFile/5052/2819>. Acesso em 08 agosto 2013.

FIGUEIREDO, Z. C. C. ; MORAIS, E. A. L. . Histórias de vida e de aprendizagem da docência de professores de um curso de Licenciatura em Educação Física. Pensar a Prática (UFG. Impresso), v. 16, p. 54-68, 2013.

IORA, J. A.; SOUZA, M. S. ; PRIETTO, adelina Lorensi . A divisão licenciatura/bacharelado no curso de educação física: o olhar dos egressos. Movimento (UFRGS) v. 23, p. 461-474, 2017

KUNZ, E. et ali. Novas diretrizes curriculares para os cursos de graduação em Educação Física: justificativas proposições - argumentações. Revista Brasileira de Ciências do Esporte,
Campinas, v. 20, n. 1, p. 37-47, set. 1998.

NOZAKI, HajimeTakeuchi. Educação Física e reordenamento no mundo do trabalho: mediações da regulamentação da profissão. 2004. 383f. Tese (Doutorado em Educação)-Faculdade de Educação, Universidade Federal Fluminense, Rio de Janeiro, 2004.

PRONI, M. W.. Universidade, profissão educação física e mercado de trabalho. Motriz: Revista de Educação Física (Online), v. 16, p. 788-798, 2010.

\section{REUNIÃO ANUAL DA SOCIEDA-} DE BRASILEIRA PARA O PROGRESSO DA CIÊNCIA (64 Edição). Mesa-redonda organizada pelo CBCE intitulada Formação profissional em Educação Física: uma antítese que se arrasta... Maranhão, São Luis: UFMA, 2012.Disponível:https://www.youtube. com/watch? $=$ WJDxzkvLN14\&list $=\mathrm{U}$ UDsdj4NGukumVZ_zpT9bF_w\&inde $\mathrm{x}=1 \&$ feature $=$ plcp Acesso em: 17/03/2014.

TAFFAREL, C. N. Z. ; LACKS, S. . Diretrizes curriculares: Proposições superadoras para a formação humana. In: Zenólia Chistina Campos Figueiredo. (Org.). Formação profissional em educação física e mundo do trabalho. Vitória: Gráfica da Faculdade Salesiana da Vitória, 2005, v. 01, p. 89-110.

TAFFAREL, C. N. Z. e SANTOS JÚNIOR, C. de L. Formação Humana e Formação de Professores de Educa- ção Física: Para Além da Falsa Dicotomia Licenciatura X Bacharelado. In: Formação em Educação Física \& Ciências do Esporte: Políticas e Cotidiano. TERRA, D. V. e SOUZA JÚNIOR, M. São Paulo: Aderaldo \& Rothschild. Goiânia, GO: CBCE. P1347, 2010.

Nexos e determinações entre formação de professores de educação física e diretrizes curriculares: competências para quê?. In: Zenólia Chistina Campos Figueiredo. (Org.). Formação profissional em educação física e mundo do trabalho. Vitória: Gráfica da Faculdade Salesiana de Vitória, 2005, v. 01, p. 111-136.

VENTURA, P. R. V. A. Educação Física e sua Constituição Histórica Desvelando Ocultamentos. Tese (Doutorado em Educação) - Pontifícia Universidade Católica de Goiás. Goiânia, 2010. 